The subject to which I shall now refer is one of great moment, namely, milk scarlatina.

\section{Milk Scarlatina.}

Mr. Power, one of the Inspectors of the Local Government Board, and Dr. Klein, have reported quite recently on an outbreak of scarlet fever spread through the medium of milk in London, and at Hendon, in Middlesex ; and the conclusion they have come to is somewhat startling, namely, that cows at the dairy farm were affected by scarlet fever as a constitutional disease, with local symptoms consisting of vesication and ulceration of the udders and teats; that the disease was communicable to the cow from the human subject, I presume by inoculation, and from cow to cow by infection; that the milk in itself was not infected, but became so in the process of milking, from infective matter from the ulcers on the udders and teats.

The inquiry is to be continued by the Local Government Board, and the attention of sanitarians and pathologists will be anxiously directed to the results : 1 , as to whether scarlet fever can exist in the cow, without having in the first place been communicated from the human subject; 2 , whether the hands of milkers can become infected by contact with the ulcers on the udders or teats, as in the case of cow-pox (this does not appear to have happened in the Hendon cases, so far as the report goes); 3 , if the cows are affected constitutionally and locally, whether the disease is communicable to the human subject only by the milk becoming infected in the process of milking. In the meantime, it is most advisable that all milk should be boiled.

If medical officers of health keep an accurate record of the milk. supply in connection with the existence of infectious disease in families, as I have myself done for years, I scarcely think such an occurrence as that reported at Hendon could very well escape, observation and detection.

\section{Conclusion.}

I may say in conclusion that in 1872 a Public Health Act became law, which enacted that the country should be divided into urban and rural sanitary districts, and that medical officers of health should be appointed; three years afterwards followed the Public Act of 1875 . From 1872 to the present time, a period of fourteen years, the progress made in the education of the public on sanitary matters has been of the most satisfactory nature,-indeed, almost marvellous, considering the great difficulties that stood in the way, namely, the unsanitary ideas which had been existing for generations, and which were handed down as a sort of unsanitary legacy, so to say ; old-fashioned prejudices had to be combated. The notion that every man's house was his castle had to be dispelled. But, of course, the greatest difficulty was, and still is, though greatly lessened, the great and very natural dislike on the part of owners of property to be put to expense ; but I am bound to say that, during twelve years' experience, I have found a large number of owners of property perfectly open to reason and moral suasion, and only too anxious to do all in their power to further sanitation; and I believe, as time goes on, and the benefits of having healthy houses and healthy surroundings become better known and understood than they are even at present, the difficulties will become gradually less and less. On the other hand, the obstinate and re calcitrant have to be dealt with; but the process is too slow and tedious. A notice has to be served, of a warning character; if not attended to, an order has to be made by the sanitary committee; this order has to be sanctioned by the sanitary authority. A certain time is given in which to do the work or abate the nuisance; if not done in the time specified, a summons is issued, and an order is made by the magistrates that the work shall be done within a certain time. All this takes, it may be, weeks before a nuisance is abated. The provincial magistrates, under the Public Health Act of 1875 , have power to inflict a fine at the time the summons is heard. There ought to be a quicker process. Dr. Dudfield, President of the Society of Medical Officers of Health, in his opening address in 1884, called special attention to the tedious method at present existing for the abatement of nuisances. The case of occupiers is a very different one from that of owners. An occupier having a nuisance dangerons to health on his premises, such nuisance being due either to his Own act connivance, or negligence, should be liable to be at once summoned before a magistrate without any notice whatever.

It is quite time that the Public Health Act of 1875 should be amended in the above and other respects, such as relegating the registration of births and deaths in the various districts to the sanitary departments of those districts. Also, provision should be made against keeping dead bodies so. long before interment, especially in warm weather. In the case of deaths from infectious disease, the process of disinfection is delayed by the deferred burial, with manifest risk to the inmates of the houses.

We in the provinces naturally look to London to take the lead in all matters belonging to sanitation or in connection with the sanitary service. London is a great and vast city ; it is the seat of the Government of the United Kingdom ; in it are located the Local Government Board and its staff of sanitary inspectors, the Asylums Board, Board of Works, Privy Council, the University of London, the great hospitals, the Colleges of Physicians and Surgeons, and last, but not least, the powerful London medical press. When the local government of London is placed on a uniform basis or plan, and thoroughly reorganised, from the example of London we shall look for great things in the extension of the science and practice of sanitation; and we may hope that State Medicine or Public Health will ere long attain the position to which it is so justly entitled.

\section{A N ADDRESS}

DELIVERED AT THE OPENING OF

\section{THE SECTION OF PSYCHOLOGY.}

\section{At the Annual Meeting of the British Medical Association, held in} Brighton, August, 1886.

BY T. S. CLOUSTON, M.D., F.R.C.P.E.

Physician-8uperintendent Royal Edinburgh Asylum; Lecturer on Mental Diseases, Edinburgh University; President of the Bection.

\section{THE RELATIONSHIP OF BODILY AND MENTAL PAIN:}

IT would be possible to say a great deal regarding the relationship or bodily and psychical pain, and the meaning of this relationship from the physiological and psychological points of view. : Even from the metaphysical point of view, a most interesting discussion as to their connection is possible. The whole of the questions regarding peripheral sensory apparatus, centripetal nerve-conduction, basal ganglionic receptive functions, and cortical perceptive action, would come in. The distinction between the nerve-fibres of common tactile and thermal sensation and those of pain ; the difference between pain and hyperæsthesia ; the connection between sensation and cortical reflex action; the connection between cortical inhibition and pain; the subjective differences between the feelings of organic well-being and ill. being; the causes of the differences between painful and pleasurable emotion, and between painful and pleasurable recollection; thenecessary association of mental pain with certain mental images and of mental pleasure with others-all these questions would have to be taken into account in such a discussion. And further, questions as to perception and memory, as to association of ideas and volition, as to the entity that feels any sort of sensation or pain, bodily or mental, and as to consciousness, would have to be touched on in any really exhaustive examination of the relationship of bodily and mental pain. I do not propose to enter on any such wide discussien of this subject. My aim will rather be to be clinical and practical in what I am to say, and, if possible, to select and draw attention to certain facts in this matter, that have come under my notice as a physician practising chiefly in mental diseases, which may be suggestive of similar and wider clinical experiences to my brethren in the same department, and to others who see more of bodily and less of mental pain than we do.

My experience has been a peculiar one, if a very close connection between bodily and mental pain in many cases of disease be not a certain clinical fact. And if this is so, my inference cannot be wrong that it is a fact of immense importance, which has not had sufficient attention directed to it.

I shall not attempt to define what bodily pain is. I shall assume that the term covers and includes all subjective bodily sensations, that are consciously disagreeable. As I shall have occasion to point out, some of the kinds of bodily pain that have a close association with mental pain, are not of the keen typical sort, such as facial neuralgia or the pain of burning, or cutting, or bruising the skin where most sensitive. All kinds of perverted sensations of the unpleasant sort are clinically associated with mental pain, in cases of melancholia. But I shall shortly define the sense in which I shall use the term psychical or mental pain. As yet, the terminology of mental symptoms in disiase has been apt to be, with most writers, inconstant and wanting in scientific accuract. If a clinical writer wished to express the fact that a patient suffering from an exhaustive chronic brain-disease was impaired in his higher volitional and original energising power-the very highest faculty of a human being - ho was often described as "lazy," "purposeless," "Tacking in energy," or "void of ambition," or in some other such vague way as 
left the impression that the man was to blame, and could help his State if he liked. If a tran's brain cortex have, through atrophy or apoplexy, become slow of response to outward impressions, its higher reffexes and its sensitiveness being dulled, he is commonly described as being simply "stupid." Medico-psychologists have not adopted the terms of the psychologists, nor those of the metaphysicians, and they have not yet invented terms of their own to express all the vary. Ing shades of disturbed mentalisation that come before them. "No doubth the attempt has been made by some of them to do so, and we have résulting a formidable array of "manias," and "phobias," and "prexias." But only a limited number of these terms has come into general use, and I have little to say in favour of their general aeceptance. But for the general use of the term, "mental pain," I am prepared to plead strongly. It seems to me that it is more true as well as more scientific than " mental depression," which is commonly understood, like melancholia, to describe the whole disease under which the patient labours, rather than one prominent symptom of it like "mental pain." When a man has suffered misfortune, or thinks he has, when he fears disaster, real or imaginary, when he sadly regrets and repents past bad conduct that has occurred or seems to have, he is in all these cases in a state of emotional distress, of painful feeling, and he suffers mental pain. When, without assignable cause, he has lost the normal healthy sense of organic well-being, and has acquired that of organic ill-being, he suffers mental pain. When with no mental, moral, or organic cause known to himself, or even imagined by him. self, he is unhappy, knowing intellectually, if he be instructed, that the only possible cause for this must be a dymamical disturbance in the bodily argan of the mental feelings : then the term mental pain expresses the fact, and implies no theory of causation. Mental pain thay be the chief symptom of a nervons disease, as neuralgia often is of a bodily one; or it may be a physiological danger sigmal calling for reflex and volitional aetion against what is inimical to the organism; or what is related to it: as when it results from the fear of injury in rushing down a steop hill too rapidly, or from the sight of a sick child. This kind of mental pain is simply analogous to the bodily pain of a cut or a bruise, or the organic disscomfort of breathing a foul gas, that has the effect of making us remove the painful part from what is curting or bruising it, or: acts as a motive to run away from the bad air. The expression mental pain covers the whole ground of normal and abnormal psychological conditions, where there is a mental feeling of distress and ill-being. Where to consciousness there ts unhappiness, there wo have mental pain. It may exist in any degree, it may assume most various forms, its duration may be a moment br a lifetime. 'It may result from fear, or sorrow, or jealousy, or regret, or repentance, or foreboding. It may be connected with disturbance 'of the social instincts, or of the morall or religious' sentiments, or of the love of life, or of the mulitiform propensities and emotions that sircle round the fanction of the reproduction of the species.

"As to the essential nature of pain bodily and mental, we can as yet bifly spectlate. It is difficult to conceive it in the abstract without first conceiting the personality, the "ego of the metaphysician, which flels. If etch earthworm feels the foot that treads it, it is just as necessary mentally to summon up the earthworm ego when we try to realise what has happened, as it is to coticeive the human personality, when a man feels the despair of a lost soul. The efforts on the patt of physiologists to discover and follow the physical process that takes place in the nerves of sensation, in the cord and basal ganglia in which these nerves end, and in the cerebral cortex where, all are now 'agreed, the final seat of feeling, bodily and mental, exists, have led to many new facts being discovered, to much speculation, and to the use of many descriptive phrases that seem to get us nearer the root of the matter. Anstie's "perturbation of nerve-function," and "dynamic disturbance," Ferrier's " physiological discord," Bain's " abatement of some or all of the vital functions," are all attempts, legitimate enough, to enable us to conceive the nature and the physical accompaniments of bodily pain.

Meynert has devoted as close attention as any living investigator to brain-functions, and he has succeeded in making intelligible Hany complicated reflex cerebral acts that before could not be expluined. By medis, first, of a demonstration of a suitable anafomical architecture in the brain, of conducting fibres in every directouri, and of receptive, co-ordinating, irradiating, and inhibitory nervetanilia, then by a careful consideration of the brain-functions,-motor, efoptici, sensory, inhibitory', and mental, - as subserved by that archi-

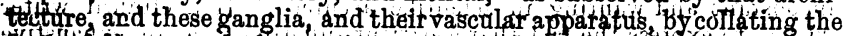

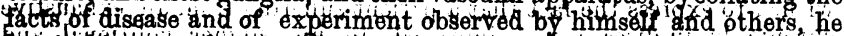

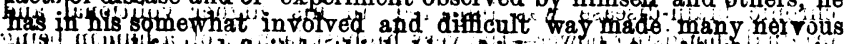

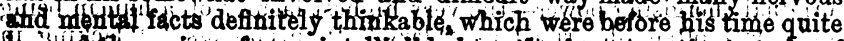
beyof the region of eten intelligible hypotkesis. A patínt study of
Meynert's work on the brain well repays the student of mental disease, and will bear fruit to the practitioner in the enlarged and more de. finite views he will bring to his practical work. A medical visit to a number of insane patients is like a journey through an untrodden land. One is surrounded by the unknown. The difference between one traveller and another is that one observes, notes, and infers; while another, bewildered by the fact that so much is strange and inexplicable; is simply confused and dulled by it.

Now, the perusal of Meynert's work tends to make us all observant of mental facts, enxious to explain them, and dissatisfied with our present state of ignorance. He is highly suggestive, and begets in us the scientific inquiring state of mind in regard to our daily wark: His hypotheses, and his keen efforts to get' nearer the mysteries of brain and mind, are stimulating in the highest degree. That is, no doubt, what we all want. He boldly faces the facts of memory, reasoning, volition, and pain, and attempts to explain them on physiological principles. With many modern physiologists; he attributes certain phases of memory to the entire organism, independently of the brain altogether. But, to explain the memory in the ordinary sense, he tries to demonstrate the fitness of the cerebral cortex, with its milliard nerve-cells, to be its seat and vehicle, by means originally of "registered images" from the senses; and he concludes that the number of the cortical cells in each brain fixes the limits of memory for its owner. $\mathrm{He}$ calls in his "associationfibres" in the brain to connect the registered images together, and so to form an association of ideas. When one such registered image in the cortex is revived into activity, we have a recollection; and when, by means of fibres associating it with another image, that other image is also revived and associated in our consciousness with the former, we have an idea of an objective something with necessary complicated qualities, and so an inference or act of reasoning. I cannot do better than quote his illustration. "Let us imagine the cortex to be a tabutla rasa; and let us present to it a phenomenon which, perceived by two sensory surfaces, would, through the mediation of the corona radiata, stimulate two distinct areas of the cerebral cortex. Let the phenomenon in question be a tamb, and let us suppose that it emits a bleating sound. The sight of the lamb will stimulate cells of the visual area, and the bleating sound will arouse cells in the auditory sphere. The lamb disappears, and the two kinds of images which it cansed to be registered will grow fainter. If, in the course of time, one of these registered images be revited through the bleating, say, of the lamb hidden in a stable, then not only the anditory, but the visual image of the lamb, will be reproduced. In the cortex, an inference is made from the sound to the body that gave forth the sound....... Inferring one attribute of a phenomenan from the presentation of another attribute constitutes an induction." He shrows by experiment how such memory and such potwer of induction can be destroyed by destroying their physical bases in the cortex, as when the centre of the visual area of a dog's brain is destroyed, and thereafter the animal does not connect the sight of $\mathrm{a}$ whip with punishment at all, though he sees the whip before him. In such ways, he renders memory and power of simple induction thinkable as brain-functions, and conformable with brainmechanism.

His theory of volition I confess I cannot follow, and it is, therefore, not made more thinkable by me. When Meynert claims credit for being the first "to insist that the processes of innervation from the 'hemispheres, which constitute what we term' volitional acts, are nothing more than the perception or memory of the sensations of innervation," he states a proposition which conveys no definite meaning to my mind.

It was necessary for me thus to refer to Meynert's theories of the co-relation of the higher mental acts with brain mechanism and brain function, in order to follow his theory of how pain is caused and felt. He, like almost all modern physiologists, does not admit any theory of pain or of sensation, as being necessary to explain the purposive movements of repulsion in the decapitated frog when the leg is pinched. $\because \mathrm{He}$ also holds that the still 'more complicated movements and other phenomens that result from cutaneotis irritation, when the brain-ganglia' are intact, the 'cortex only being removed, are all ex. plicable without any sensation of pain. He homologates Schiff's ex perimental discotyery, that, when the conduction through the grey strbstance of the cortex has been impaired by injury and disease, cutzneous irritation produces therely tactîle and thermal sensations, but no sensation of paiti causing a condition of analgesia. We thay have an imperfect brain-cartex in fact, which, can feel, but can-

1 This, and the sacceeding possages, nire quoted from Psychtiatry ' $a$ Clinical Treatise on Disedses of the Fore-Brain, based upon a Stwaly of its : Strueture; Pronic-
tions, and Nutrition. By Theodore Meynert, M.D. Translated by B. Bachs M.D 
not cteel pain, by reason of that imperfaction that the proved slowness of nerbencanduetip through the grov 1 substance of the brain, as companedi rith iss!ponduption through or peripheral nerve (twolve timas) as longl, aqdording to Helmholtz), is owe ong to a "resiatance" to such cenduation of impressions in the cortex Ho maintains that " with an increase in the number of museular groups excited to action by a reflox irritant, an increase in the resist ance to nervo-oonduetion, goos hand in-hand." The "irradiation of any irritation," ha thinks, "s has agreat influence upon, the character of the pain-sensation ifron sajd ipritation." "The sensation: of pain, therefore," he says, "is first attended both by a reflex morement, and by an inhibition of nerke-cendaction in the grey gukstance of the opinal cord. It is evident that that inhibition resulting fram resigtanes introduced in nerve-tracts acempanies the simplest reflex prooesses, while consciousness in the main reeognises the inhibition as pain.", In short, Meynert's theory is that a slight momentapy' prigk causes little pain, becanse it only excites in the cord a slight and limited raflex movement that takes place ot once, or is at onceseasily inhibited by the physialogical resistance of the grey matter, not tend in' to spread or "irradiate" through the grery substance of the cord in to extensive reflex morementa gll over the body ; while an extensive bunn of the skin would eapse the most tremenous and long-continued reflex movements on both sides of the hody if not " inhibited" in the grey matter, this process of intense inhibition betarg recognised by consoiouspess as intense pain caused by the burn

Then he brings is the reflex: effects of peripheral irritation on the cinealat apporatus of the blood-vesels, "the centres for which are located in the spinal gxey mptter. The extent and in tengity of this in fluence, vary direatly, with the amount of the irradiation of the original atimalibnt impulge;" The arteries of the spinal cord contract reflexly in this way, and also the carotids and all their branches, supplying the brain. In thiswsy physical pain prodpces swooning; and expidins why, in former, conturios, when or offeseion whs, extorted in court by torture; the penon ireriminated Fonld fall asleop whilo undergoing the pangs of tho rack

Then he points; out that " the constriction of the arteries, by impeding the ;espiration of the nervous elements, must necessarily engender a dyspnotic phase of nutrition : it will modify the ohemical changes going on in these elements : And as a further result of this, we shall find the sensoxy stimulus associated with the irritation, revalting from certain degree of dyspncetic intoxication." Ho maintrins thet this "dyspncea," or non-oxygenation of tissues, always excites : "repulsiye mavements.", "Movements of repulsion," accarding to Meynert, are: the result of, and always caused by, sensory impressions adverse to well-being or life, such sensory irritations causing immedipt 6 ly inhibition of nerve-conduction increased arterial pressure, and de-oxygenation, 'as. well as impaired natrition 'of the nerve cells, those effects being recognised by consciousness as pain. "Movements of aggression," again, he applies to all those movements resulting from agreeable sepsory stimuli, that tend towards the wellbeing of the organism and to prolong life, that are attended by the frae transmission of nerve-force, by vaso-motor dilatation, a functional hyperæmia of the nerve-centres, and (as be puts it) "an apnotic phase in consequence of the increased tissue breathing of the nervous elements." "The unhampered purposeless movements of a lively animal, the song of a bird, the merry bark of a dog, are in reality movements of aggression." He concludes that the movements of repulsion, and those of aggression, are equally reflex, because they can both be produced, the one by irritating stimuli, aud the other by agreeable gentlo non-painful stimuli, in decapitated frogs-as when gentle friction between the shoulder-blades made them croak, and slight pressure and friction of the breast and inner surfaces of the arms, is fallowed by the sexual embrace, while the croak cannot be thas elioited nor the sexual spasm excited, "if any part of the frog's body be at the same time touched with acetic acid."

He concludes, also, that "irradiation (of a sensory irritating stimulus) meets with severe and widespread resistances in the grey substance of the cortex, as well as in the central grey substance" of the cord. "In this respect, the pain answers to a sensation of inhibition. The in hibition obstructing the path of the irradiating stimulus calls for an exhausting amount of excitation, and thas effects, inhibition of other cartical functions, and sets a limit to the activity of the cortex; it inhibits attention, thought, and the association of idess as well." Here Meynert is talking of the mental effects of bodily pain ; and I shall have occasion to d well strongly on still more marked inhibition of mental acts reoulting from mental pain.

"W. mey say that the aensation of pain is associated with increased nerrowing of the arteries. But contraction of the arteries implies a chamilel change," a deficierrcy of axygen ard of nutritive elements to

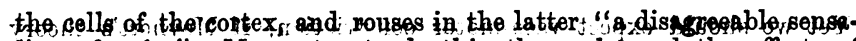
tion of pain." Meynert extonds this theory beyond the effects of

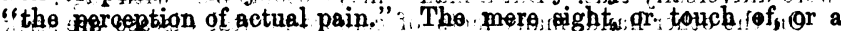
sound from, objects which ere asqooigted in the forebrain (cortex), with the idea of pain, danger, or death, excite, as much as the poin itolf movements of repulsion, and oreate in the cerabral cartex all the con. ditions of subjective torture, which we have learned to mgard a concomitants of real pain. The reminiscences of painful disagreable abjects arouse all the correlated physiological sensations accompan jign genuine objective pain, namely, inhibition, increased arteriel pressure, dy ypnostie phases of nutrition, and repulsion. We are in thisl way brought by Meynert into the region of mental pain, which, iq thus physiologically and causatively co-related with bodily pain. He says, in regard to painful emotion, peychicel pain : "That painful omotions depend selely upon assoeiations, upon inferences pointing to the perception of pain, can be proved by a simple analysis of the abjects which exroite pain. The retinal images of a tame and of a wild; animal, of an indifferent person and of one whom we fear, are projectrod upon the same retinal area, possess the same colour, and the same intensity of light. An indifferent red fluid and blood leave the same impression upon the retina ; mere perception cannot excite emotion, but the associations united to the former cap. ot is, therefore, the mech mism of the hemispheres only-the progess of thoughtm whigh exeites psychical pein and movements of repulsion, as well as the arterial contraction: which may terminato in swooning apd in ongendering fear and a feeling of incapacity for aotion." And he farther points out that : sensory impressions are not needed to rouse psychical pain : 'recollections of painful impressions may revive such alssaciations.;' And he takes, as an illustration, the effect of the news of therdeath $\mathrm{Qf}$ a friend, whose image in the brain was connected with mandfold pleasurable associations. 'S Stoh news would cause inhibition af all those associations," "marked inhribition of ! nervous impalses] from the forebrain (cortex) excites like the inhibition of poinful sensory stimuli or the suggestion of torture a conception of the impossibility of counteracting this inhibition; which may ultimatelys lead to suicide.

"Inhibition (in the cortex) is attended by omotion and psyehical pain;" "functional hyperæmia $a_{1}$ is the physical concomitant of thonght," and also of pleasurable emation. "The majonity of mental processes are based upon reminiscences on memories which hater, emgaged the functional activity of widely separated regions of $_{1}$ ithe cortex, whence it follows that the functional hyperemia will inyariably affoet circumscribed areas at some distance from one another." And, afterwards; he shows how, anatomically, that over " "tha brodad expansion of cortical surface the large number of arteries descending vertically, forton the pia in to the cortex are well ealeulated to permit paintial funotiona hyperæmia of separate cortical areas.": He quotes Fechner, 'to!show that in ordinary sane wakefulness there is, after all, only a "limited wakefulness, with extensive areas of the cortex in a state of functional repose, and, therefore, of anæmia." "The blood-supply in the brain is determined by the functional hyperæmia of the areas called into activity." And, at this point, he goes carefully into the most important question of the brain's rigid walls, of the venous cavities, of the lymphatic spaces; of the cerebro-spinal fluid, of the brain-movements, as these affect the blood-supply and the functional activity of the organ. The relationship of functional cortical activity to its own blood-supply, and its vaso-motor condition generally, is admitted by Meynert to be very obscure. But it is very important in considering normal and abnormal brain-working. That the cortex is a vaso-motor centre for itself, there can be no doubt whatever. He concludes that commonly, and in health, "the functions of the forebrain (cortex) inhibit one another according as one or the other happens to predominate " at the time; that is, intense thought will inhibit emotion, intense attention to objective sounds will inhibit thought, etc.

Maynert's theory of the conditions of the brain and cord, which produce pain bodily and mental, may not be confirmed; but, at present, no other hypothesis has gone so far as his in attempted explanation of the facts. No other is so definite, or is founded on what appear to be physialogical laws of nervous action. His theory may be said to hold the field at present. We moy yet discover some delicate mothod of directly measuring the inhibition that is being exercised by a nervous ganglion, or we may yet discover some direct method of measuring the vaso-motor condition of the brain-cortex in its different areas, and so be able directly to prove or disprove his theory.. Theve are many apparent inconsistencies of this theory with facts. For instance, to take a very obvious and common fact : when the pasqion of angeran undoubted kind of mental pain-is excited in the brain, we have the terminel, branches of the external carotid over the face, at first very dilated, as the vigorous " movements of repulsion." are exeroised 
Yet we should expect vaso-motor constriction, if Meynert's theory were universally true. But a man " may become pale with rage."

On the other hand, many facts of cerebro-mental disease are strikingly in accordance with it. Take, for instance, the case of a general paralytic in the end of the third stage, when the brain-cortex is degenerated and atrophied to a greater extent than in almost any disease we know. Irritations of the skin in such a case, where the degeneration does not happen to have affected deeply the gray matter of the basal ganglia and spinal cord, will cause no pain, but will set up most extenBive and violent reflex motions. I have such a case where a elight prick, or even blowing on the skin of the neck, will put every voluntary musele of the body into reflex action, and a strong sudden snap with the fingers on his chest will produce a slight convalsion. In such a case there is no inhibition in the cortical ganglia, and so there is no conscious pain; but extensive "irradiation" of the irritation thronghout the motor centres.

I think it is a reasonable inference that the condition of the cortex, which directly causes the subjective feeling of bodily pain from a burn of the finger, will be the same as that which causes the pain of typical nenralgia of central origin, and that the cortical state cannot be very different in a woman prostrated with grief on account of the loss of a child, from that of another who has the delusion that she has, by her misconduct, imperilled the salvation of her family. At all events, a definite theory, like that of Meynert, adds an additional interest of a acientific kind to the following clinical facts in regard to the common essociation of bodily and mental pain.

One of the most common of all clinical facts in a study of the inception of melancholic conditions, that is, of mental disorders wher mental pain is the most prominent morbid psychical symptom present, is that the pationts have, at a former period, been subject to bodily pain; of some kind or other, usually of the head, and of a neuralgic kind. The typical case of this is that of the woman with a neurotic heredity, who was hysterical at adolescence, who suffered from neuralgis badly at times, till the age of forty, who then, when anæmic and overworked, had a domestic affliction which produced physiologicalmental pain, and that again induced sleeplessness and loss of flesh. Frontal cephalalgia, pain in the 'eyeballs, and morbid sensitiveness to sounds, were: very prominent symptoms in the case, till the grief deepened into pathological melancholia, with perversion of reasoning in the shape of delusions that she had been in some way the cause of her child's death. When this condition set in, the cephalalgia disappeared along with the pain in the eyes and the auditory hyperæsthesia ; but, so long as she could describe her own sensations, she complained of a peculiar foeling in her head, which she said was new and entirely unlike the old neuralgia.' It consisted of an unpleasant sensation as of a " creeping feeling inside the skull." During the very worst part of the attack she had no self-control at all, and much motor excitement in the shape of restlessness, moaning, etc.; and at this stage she had no subjective sensations of any bodily pain or paresthesia of a disagreeable kind, but she clearly had a general sense of organic ill-being After the acutest stage passed off, she was for a time mentally torpid rather than mentally pained, and when tested she was less sensitive to bodily pain. A crop of boils came out on her, and caused no very great pain. Yet she was not anæsthetic. In reality, at this stage she laboured under a certain degree of mental and bodily analgesia, having bodily sensation and mental feeling, but not bein susceptible of any keen pain, mental or bodily. This stage passed off, and she began to feel the old frontal cephalalgia; and from my previous experience, I knew then that the attack of melancholia was drawing to an end. As her red corpusoles increased, and her body weight improved under proper treatment, the headache gradually passed off. The neuralgia and the melancholia both inhibited nutrition, sleep, volition, the appetites, and the power of continuous thought.

Now such a clinical connection of bodily and mental pain-symptoms, as oxistod in this case, is far too frequent to be a coincidence of unrelated phenomena. They both form part of one disease, in my opinion, a disease of the brain-cortex, with sensory, trophic, motor, vaso-motor, and mental symptoms, the sensory and the mental being essentially bound up with the trophic, but the motor and the vasomotor being secondary. Looking on the sensory function of the braincortex as being, from the evolutional point of view, an earlier development than the mental, and as being on a lower plane and of lesser im pertance, teleologically, as it were; I regard such a case as an example of the lower function being first affected by a disease, which not being arrested in that lower plane of nerve-action, passed gredually up into a higher region of the cortex, that of mentalisation. But did the sensory disease really cease; as it appeered to do, aftel the melencholia'began? or was the disedse there, but the bodily pain not felt? No one can doubt the very close association of sensation with montalisation ; and it is quite certain that there is no dividing line' between the higher reflex funotions and sen'sations. In the cases of stupor and very deep dementia, all thesefunctions are almost équally paralysed. A sensory act can excite or inhibit reflex action, 2 mental act can excite or inhibit both. It may be taken as a physiological fact, too, that there is, in every brain, just a certain innate capacity to feel bodily or mental plessure or pain ; and this power of feeling may be used up either chiefly as bodily sensation; or chiefly as mental emotion; they are, in fact, transferable. I think the facts go to show that, in the case I have described, when the feeling of mental pain began, it took the place of the bodily pain. The higher plane of the cortex having taken on a disturbed acting, the lower plane of bodily feeling ceased its perverted action, passing into a partially anæsthetic state, into which the higher plane also passed afterwards, in the mental analgesia after the stage of motor excitement. But why the return of the neuralgis in a modified form as the mental pain disappeared? In any explanation of a clinical fact in neurology, we must take into account the laws of nervous action physiologically and pathologically, and must often refer to the facts of the simpler nervous disorders to explain those of the more complicated. Now, in this case, we find an analogots faot in a motor disease. Many epileptics suffer from severe neuralgic headaches, and especially : so just before a fit. When the fit has passed over, there is, immediately after the unconscious stage, a period of confusion and torpor. While this lasts there is no headache, but, as normal mental activity returns, there is frequently areturn of the headache, or of its neurotic equivalent, a morbid mental excitement for a time. It is to be kept in mind; too, that, in some of the cases of melanohelia of which I have taken this as an example, almost the normal condition of the patient is one of head. ache, or being on the verge of it.

The striking fact we have to bear in mind, is the definite clinical relationship of bodily and psychical, in this class of cases not occurring contemporaneously but in sequence. Certainly 'Meynert's hypothesis of resistance to the irradiation of nerve-conduction in the cortex, together with vascular contraction and dysproea of the tissues, as being the immediate cause of pain bodily or mental, would fit in 'with all the clinical facts of euch a case

When, daring the period of bedily or mental pain, the patient "loses control over himself," that is, when the resistance to the nerveirritation passing into the motor centres ceases, and the patient stamps his feet, shouts, weeps, or rushes about, there is sensible relief to the pain bodily or mental thereby; just as strong motor action, such as setting the teeth or seizing something violently in the hand, modifies the pain of a surgical operation.

Though the intense pain of the neuralgic kind disappesrs when mental pain becomes intense in melancholis, yet we have in the majority of such cases a perversion of normal sensibility; common or special, of a painful kind accompanying the mental pain: It often takes some trouble to find this out in many of the patients, for they are so occupied with their mental misery or their melancholic delusions that they do not speak of such bodily feelings, except indeed in the hypochondrical class of melancholics. The sensetions to which I allude are usually referred to the head, and they are of an immense variety. Perhaps the most common are a feeling of emptiness in the head or of fulness, or of weight. Such patients frequently complain to me of feeling as if their brains were gone, and air had taken their place, or as if their skulls were filled with lead. Some of them complain of a throbbing foeling or of a prickling feeling, or of a creoping feeling, or of a hot or a cold feeling in the heads or oter their scsilps. One man lately said he had a nasty foeling " as if his body hung from his head ;" and when he sneezed (which he is averse from doing) as if something burst in his head ; enother patient says he his a painful feeling of a stick passing from one painful spot in his head to an incisor toeth. He had toothache lately, but he said this was quite a different kind of pain. A ledy told me lately; that, when she first became melancholic, she had a peculiar "indescribable" feeling in the top of her head, especially when she was tired, quite different from an ordinary headache.' In some cases, it takes the form of special sense hallucinations or perversions. One lady told moj after recovery from melancholic resistive (delusional) stupor; that when at her wonst she sometimes saw objects of a red colour for example, the water in her bath, and that stationary objects would seem to enlarge and diminish in size, would ceme near and recede' as she' looked at them:' She' would hear unpleasant sounds and 'voices' wnd horrible reminisoences and sights would project themselves actoss her consciousness; as if from without her $y$ ind the sight of common things would is seem to indicate painful meanings, for exermple, the laces of her boats showed that she was to be bound, whipped, and tortured. Her foed often 
tasted of nastiness to her. All these things no doubt were symptoms of disturbed action of the special sense-areas of the cortex.

Those perverted painful sensations are not confined to the head, or to the special senses. They are referred in some case to the chest, 'to the abdomen, and to the limbs. Some melancholic patients complain of pains in the region of the heart, and some of teelings of constriction in the chest, as if they conld not get breath. Most frequent of all sensations, except those in the head, are sensations of sinking and pain, of fulness, of " anxiety" in the epigastric region. Certain forms of melancholia are so characterised by abdominal symptoms, that they may be fitly called "visceral" cases of the disease. Such organic sensations of discomfort often precede the mental depression like the headache, but, unlike this, they seldom pass away when the mental pain begins. Some patients can tell when they are going to have an attack of melancholia, from the beginning of such sensations.

Spinal pains and discomfort, and even lumbago, are common. I have now a case of aggravated resistive melancholia under my care, whose attacks have always been preceded, and their earlier stages accompanied, by attacks of lumbago, which passed off when the mental pain became in tense.

Pains resembling sciatica are not uncommon in the legs before melancholia supervenes; while feelings of stiffness and of cramps in the limbs I have also known. Perverted sensations with regard to the size of the head and limbs are by no means uncommon. I had a patient who said he felt as if his head were enormously large, and another who felt as if his legs had grown quite diminutive.

Perverted sensations of heat and cold are common. One melan cholic says he has a constant feeling of cold, another that he feels hot subjectively - the actual bodily temperature in both being just under normal, as is usual in most varieties of melancholia, except the excited form. Sensations of prickling, of formication, of itching in the skin are not uncommon. I have seen many patients, again, who complained of "a want of feeling all over the body, a deadness," as if they carried about a corpse instead of a living body.

I have never been able to believe that such painful and perverted sensations commonly originate in vascular abnormalities. On the contrary, the facts seem to point to a purely nervous origin; but no doubt they are always accompanied, and commonly kept up, by vasomotor abnormalities ; though the facts of megrim and other neuroses seem to point to pain being readily caused; in some cases, by vasomotor dilatation and paralysis.

My recent experience, since my attention was strongly directed to the close relationship of mental and bodily pain, has been that in nine out of every ten cases of melancholia, if carefully questioned during and after the attacks as to their sensory history, we shall discover, as a clinical fact, painful perversions of bodily sensibility in some shape or other, standing preliminary to or accompanying the attack. Melancholia is not a mere mental disease; it is a general disease of the brain-cortex, usually implying a combination of mental and bodily symptoms, the latter chiefly consisting of neuroses of sensibility, and commonly accompanied by vaso-motor trophic neuroses.

Many every-day facts show that mental and bodily pain can take the place of each other, and in many cases, indeed, cannot co-exist in any great intensity. I have known a painful burn stop the mental pain for the time in melancholia. All of us have seen the transient good effect in some cases of a blister; while, on the other hand, bad news, or even the painful mental anticipation of the dentist's forceps, will often cure toothache. Sometimes a normal and physiological mental pain, such as the news of the death of a child, will inhibit and cure the abnormal pain of melancholis.

Another relationship is frequent. Severe bodily pain long continued will frequently bring on melancholia. I have seen two cases lately of ladies, who, subsequently to painful surgical operations, became melancholic. I have seen melancholia come on after a painful attack of rheumatism. In such cases, no doubt the nutrition and the general nervous energy would be thus run down.

There can be no question whatever as to the general similarity of many of the typical cases of hereditary neuralgia and of hereditary melan. cholia in the bodily condition of the patients, both being thin, both bad sleepers, bad digesters of their food, both over-sensitive, both intellectual but wanting in staying power for continuous mental work and in surplus energy bodily and mental, and both manifest, in certain cases, a marked tendency to diurnal aggravations. Both may arise from local sources of irritation, bodily and mental. Both inhibit volitional action and energy, emotion and sexual feeling. And, unquestionably, the treatment found useful for both diseases is the samo; change of air and scene, a generous fattening diet, cheorftul company, systematic regimen and division of time, iron, quinine, tonic nerv stimulants, volitionial energy rightly roused, and fixing the attention on objective things of an agreeable kind. In short, whatever nourishes the body, increases the red blood-corpuscles, and oanses functions hyperæmia, and improted nutrition of the brain-cortex, cures both diseases.

In certain hereditarily neuropathic families it is very common for one member to be subject to neuralgia, and another to melanoholis ; while we have all seen hereditary connections between the two diseases; such as a neturalgic móther having a melancholic son. I have seen several cases now of circular neurosis, where an intolerable neuralgia formed one part of the circle, and deep mental misery formed another:

In hypochondriasis, we have a disease where there is neither acute bodily nor intense mental pain, but a combination of both in modified and mixed-up way. No one can doubt who has seen a strong intellectual man pass through an attack of hypochondriasis, or of melancholia of the hypochondriacal type, and seen him recover again, that these were real diseases, caused by disordered energising of the brain-cortex, however much the symptoms during the attack seemed mere "imaginations," and the strange conduct appeared controllable by the will, if the patient had chosen to exercise it. But there are few mental diseases where a man's normal volition, his foelings, his habits, and his power of working, will be more inhibited than in this. The pains and discomforts, the imaginary disorders of function, and the general sense of organic ill-being of the hypochondriac, I look on as resulting from an equal disturbance of the mental and sensory portions of the brain-cortex ; just as in ordinary melancholia there is an unequal disturbance, the mental portions being most uffected. No doubt, the areas that control and specially represent the organic viscera, and their special nervo-ganglia are specially disturbed in fanction in these cases.

From the prophylactic point of view, the general association or melancholia with sensory disturbances has a special value. Som'o pain or sensory perversion usually preceding the mental disease, the physician can take early measures of prevention. How many attacks of melancholia could be averted, if proper treatment were only adopted in time?

It appears to me that physicians in general practice frequently do not realise the significance of slight mental depression, accompanying or following neuralgie or sensory perversions, and that psychiatrists often do not-sufficientiy think of the sensory symptoms in the stady and treatment of melancholia. The borderland between nearalgis and melancholis I look on as a very slight one indeed. They are both manifestations of one type of the neurotic diathesis. The sest of both is in the brain-cortex, and in the same part of the cortex, thergh not in the same cells. The actual cortical conditions under which the mental and the bodily pains arise would appear to be the same ; there. fore, it seems clear that they should not be studied or treated apart from each other.

\section{AN ADDRESS}

DELIVERED AT THE OPENING OF

THE SECTION OF PATHOLOGY,

At the Annual Meeting of the British Medical Association held in Brighton, August, 1886.

BY JULIUS DRESCHFELD, M.D., F.R.C.P. Professor of Pathology, Victoria University : Physician to the Royal lnfirmary,
Manchester : President of the Section.

THE RELATIONS OF PATHOLOGY ; AND ITS STUDY

GrNTLEMEN, - In taking the chair in this section, I wish in the first place to express my sincere thanks for the great honour conferred on me by my election to the presidency, a post which has been held by most eminent men in this country. In spite of all my endeavours, I" arm afraid I shall be but a feeble successor to them. I will, however, do my best to prove myself worthy of the confidenoe placed in me; and I am! sure $I$ shall not ask in vain for your kind indulgence.

$\mathrm{My}$ first, and by no means easiest duty, is to say a few words intro. ductory to our work. In doing so I have aroided taking up any speciel subject of patholoos, as the discussions and papers tready announced provide ample material in that direotion. Moreover, as our Joorsil gives from time to time an excollent retrospect of recent pathologicid researches, I do not propese to occupy your time with such a rotrospect on the present occasion. I will only ask your attention for a very short time while I offer a few observations on the 